\title{
The more things change ... reflections on midwifery
}

$\mathrm{T}$ he growing interest in midwifery reminded me of a personally important and, in some respects, highly unusual event that took place in London, England 46 years ago.

At that time, we were spending the second of a two-year fellowship in social pediatrics in England, living barely within our means in that stillwonderful city. Part of my training meant that during the previous fall we spent two months on the Isle of Wight as part of a team conducting a survey of children. My task, as the only pediatrician in the group, was to travel around the countryside interviewing parents of the subjects. My wife's main responsibility was to look after our two-yearold daughter and figure out how to keep us from freezing. The seaside flat we rented was lovely when the sun shone, but as was customary in those days, it had no central heating. So, at sundown, a bone-chilling process began. The single bar in the electric fireplace only served to keep my eating hand supple during dinner and as my wife is lefthanded, she too avoided starvation thanks to that bar. But, as the temperature dropped, the bar no longer sufficed and there was only one path to survival; the bedroom with layers upon layers of quilts. And that is how our son Charles came to be conceived 45 years ago.

After the statutory waiting period, the delivery was booked at St. Mary's Hospital Paddington where I had a lowly staff appointment. As the time approached, we experienced growing anxiety lest our earlier encounter with childbirth should be repeated. That one, two years previously, was at a prestigious Boston maternity hospital. Somehow, that hospital had not yet received any of the important messages about the role of fathers in the birthing process (beyond the usual prerequisites). As a consequence, while the anesthetist struggled apparently unsuccessfully to administer a spinal block - the preferred technique at the time - to a woman with known lower back problems, I was left to wait in

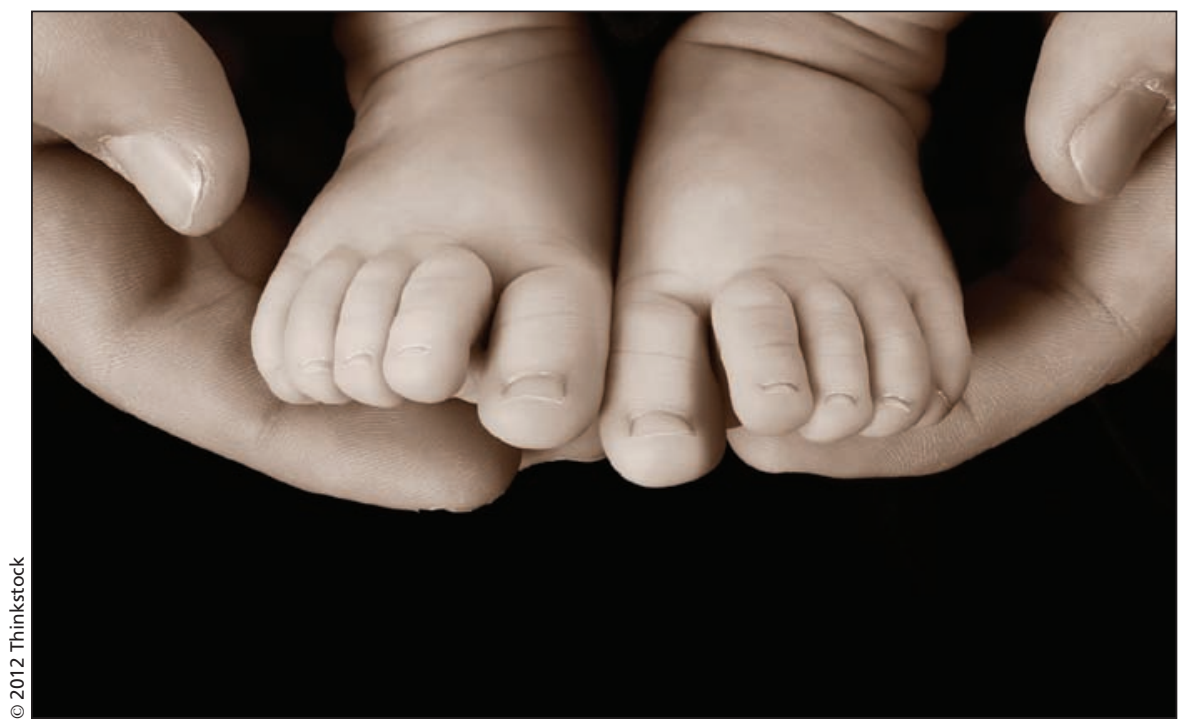

the corridor. And wait I did, for nearly 12 hours, with nary a word from the inner sanctum. By then I had long since passed the point where I had concluded that a disaster had occurred; the only question was whether it involved my wife, our child, or both. Then, by chance a pediatric colleague came strolling by.

Protocol permitted him - a junior resident on rotation - to enter the delivery suite. He soon returned with the joyous news that my wife and daughter were both alive and well. Some while later, I was invited to join them: to look but not to touch. Much the same was true for my wife - she was not given the baby to hold, and the pain of the unsuccessful anesthetic attempts was such that she probably could not have cared less.

With these memories burning far too brightly in both our minds, soon after labour was well established, we drove to St. Mary's and checked in. The admission procedures were ridiculously simple. An hour or so later, with no fanfare, I was invited into the delivery room where I was introduced to the nurse midwife. She was clearly in charge. The obstetrician and I stood by patiently and observed (he, nonchalantly; me, in complete awe) as she gently but firmly managed each stage of the delivery. Only at the very last minute, after crowning was complete, was the obstetrician permitted to do his thing. He caught the baby, cut the cord, and moments later I was holding our first-born son. Smiles all around.

A few minutes later I was handed a glass of champagne. I thought I was familiar with most British customs, but this took me completely by surprise. In fact it was not customary; it was simply a celebration of the final delivery performed by this extraordinarily gentle, confident, and immensely competent woman. We drank to her health and future, and, incidentally to the latest member of the human race - now, 46 years later, a dedicated but far too hardworking family physician.

I thanked her profusely and even remembered to also thank the Queen's obstetrician, the late Sir George Pinker, who she had permitted to assist in this delivery. And then I wondered if she permitted him to participate more when Prince Charles was delivered.

A lesson for our times?

\section{Barry Pless MD \\ Professor Emeritus \\ Pediatrics and Epidemiology \\ McGill University \\ Montréal, Que.}

CMAJ 2012. DOI:10.1503/cmaj.111967

All editorial matter in CMAJ represents the opinions of the authors and not necessarily those of the Canadian Medical Association. 